\title{
Utilização da biomassa de uva como biossorvente na remoção de metais pesados de águas residuais
}

\author{
Utilization of grape biomass as a biosorbent in the removal of heavy metals \\ from wastewater
}

\author{
Larissa Fernanda Finazzi da Costa ${ }^{1}$, Daiana Maffessoni ${ }^{2}$ \\ Universidade Estadual do Rio Grande do Sul. \\ E-mail: ${ }^{1}$ larissa-costa@uergs.edu.br; ${ }^{2}$ daiana-maffessoni@uergs.edu.br.
}

\begin{abstract}
Resumo: Em 2018, na região da Serra Gaucha foram produzidos cerca de 132,6 milhões de quilos de resíduos sólidos provenientes das atividades da viticultura e que poderiam ser utilizados como matéria prima para o processo de biossorção de metais. O objetivo do presente trabalho foi avaliar o potencial da biomassa de uva como biossorvente na remoção de metais bem como as melhores condições de operações dos parâmetros estudados. A primeira etapa foi o pré-tratamento na qual o engaço e bagaço foram lavados separadamente, secos e triturados. A segunda etapa foi a determinação da melhor composição entre bagaço e engaço foram testados diferentes composições para a remoção de cobre pela técnica de espectrofometria, dentre os melhores resultados optou-se por trabalhar com a proporção 50/50. A determinação do ponto de carga zero foi realizada utilizando soluções de ácido clorídrico e hidróxido de sódio e o resultado foi de 5,9. Nos ensaios de otimização da biossorção utilizou-se solução de $\mathrm{CuSO}_{4}$ e analisou-se o tempo de agitação e pH ideal. Os tempos de agitação analisados foram 30 a 90 minutos e para pH ideial foram testados no intervalo 2 a 12. Os dados de equilibrio surgerem que a adsorção seja em monocamadas, melhor representado pelo modelo de Langmuir,sendo a capacidade máxima de biossorção de $10.000 \mathrm{mg} \mathrm{g}^{-1}$. Tais resultados demonstram que a aplicação da biomassa da uva como biosservente é uma um técnica de $72 \%$ de grau de eficiência para a remoção de cobre.
\end{abstract}

Palavras-chave: Uva; Biossorção; Remoção.

ABSTRACT: In 2018, in the region of Serra Gaucha, about 132.6 million kilograms of solid waste from viticulture activities were produced and could be used as raw material for the biosorption process of metals. The objective of the present work was to evaluate the potential of grape biomass as biosorbent in the removal of metals as well as to optimize the process. The first step was the pretreatment in which the stalks and bagasse were washed separately, dried and ground. The second step was the determination of the best composition between bagasse and stalks were tested different compositions for the removal of copper by the spectrophotometric technique, among the best results we chose to work with the ratio 50/50. The determination of the zero loading point was carried out using solutions of hydrochloric acid and sodium hydroxide and the result was 5.9. In the biosorption optimization assays $\mathrm{CuSO}_{4}$ solution was used and the agitation time and ideal $\mathrm{pH}$ were analyzed. The agitation times analyzed were 30 to 90 minutes and for ideal $\mathrm{pH}$ were tested in the interval 2 to 12 . The equilibrium data show that the adsorption is in monolayers, better represented by the Langmuir model, with a maximum biosorption capacity of $10,000 \mathrm{mg} \mathrm{g}^{-1}$. These results demonstrate that the application of grape biomass as a bioserver is a high efficiency technique for the removal of copper.

Keywords: Grape; Biosorption; Removal.

DOI: 10.18554/rbcti.v4i2.3710 


\section{INTRODUÇÃO}

A preocupação com a presença de poluentes em meios hídricos vem crescendo, justificando a busca por técnicas alternativas ou adicionais às aplicadas nos processos convencionais de tratamento de água.

A fim de satisfazer os padrões de qualidade da água e atender a normas legislativas emergentes (YOUNG et al., 2006), a concentração de metais tóxicos em águas residuais deve ser controlada (KIM et al., 2005), uma vez que estes elementos químicos possuem densidade elevada e são tóxicos mesmo em baixas concentrações (BHARGAVA et al., 2012). Segundo Guijarro-Aldaco et al. (2011), as águas residuais de várias atividades industriais são uma importante fonte de poluição ambiental, devido a elevada concentração de metais tóxicos em sua constituição.

O estudo de tecnologias para remover metais se faz cada vez mais presente, pelo fato dos metais não se decomporem como a matéria orgânica, e sim acumularem-se nos níveis tróficos das cadeias alimentares (SEOLATTO, 2005).

Dentre os diversos métodos de tratamento de efluentes contaminados com metais tóxicos as técnicas mais utilizadas são de coagulação/precipitação, troca iônica, extração por solventes, osmose reversa e adsorção. Os processos que envolvem troca iônica e adsorção com carvão ativado, são relativamente caros, pois envolvem alto custo operacional e com equipamentos. $\mathrm{E}$, processos como coagulação/precipitação demandam o consumo de muitos produtos químicos e consequentemente geram muito lodo Por esses motivos tem-se buscado novas alternativas de tratamento, as quais sejam eficientes e mais baratas que os processos já utilizados. Uma boa proposta de tratamento para esses resíduos é o processo de biossorção (OLIVEIRA; SILVA, 2011).

A biossorção ou bioadsorção ocorre devido a presença de diversos grupos funcionais que constituem a biomassa, tais como celulose, proteínas e lignina. A bioadsorção de metais não é baseada num único mecanismo. Ela é composta por vários mecanismos que quantitativa e qualitativamente diferem de acordo com a biomassa utilizada, sua origem e forma de processamento. Os principais fatores que podem interferir diretamente no processo de biossorção de metais tóxicos em ambientes aquáticos são: $\mathrm{pH}$, tipo de cátion metálico, natureza e concentração do material adsorvente, salinidade, carbono orgânico dissolvido, alcalinidade e competição entre cátions (THOMÉ, 2008).

Um dos resíduos ricos em tais compostos é a biomassa da uva, durante a elaboração do vinho, os compostos como celulose e lignina são retidos no mosto durante a etapa de maceração isso ocorre porque tais substâncias são provenientes das partes sólidas da uva, uma grande proporção desses compostos ainda permanece retida nos tecidos vegetais remanescentes. Estima-se que, para cada seis litros de vinho produzido, um quilograma de bagaço seja descartado (TOURNOUR et al., 2015).

Estes resíduos são geralmente subexplorados sendo utilizados na alimentação animal (com baixo valor nutricional) ou como adubo, e também são descartados representando um problema ambiental. No entanto, eles podem tornar-se produtos com retorno econômico potencial por serem fontes de compostos bioativos que podem ser aproveitados. E são pouco exploarados no processo de remoção de metais pesados em águas residuais. 


\section{MÉTODO}

A Figura 1 apresenta o fluxograma das etapas do trabalho desenvolvido.

Figura 1: Fluxograma do proceso desenvolvido

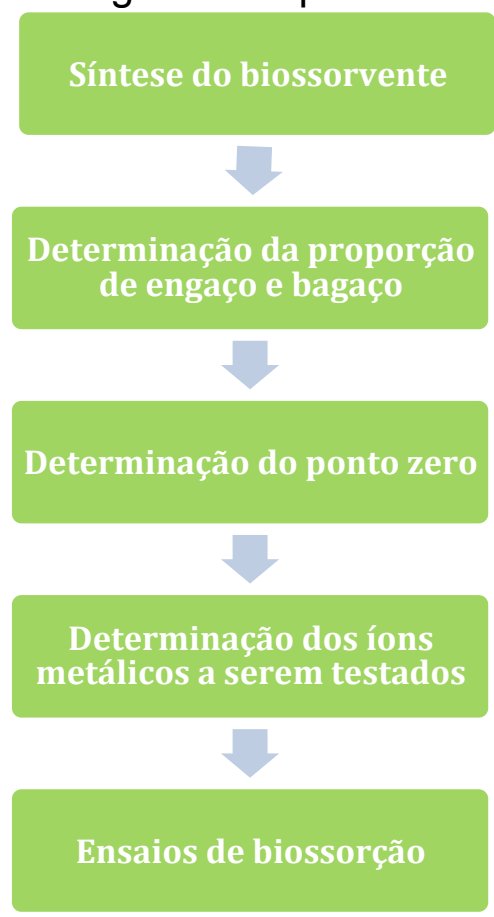

\section{Síntese do biossorvente}

As amostras de engaço e bagaço foram cedidas por um produtor da cidade de Bento Gonçalves e posteriormente passaram por um pré-tratamento. O pré-tratamento é composto pelas seguintes etapas: lavagem das amostras com água destilada; secagem em estufa, sendo que o engaço foi seco a $80{ }^{\circ} \mathrm{C}$ por 24 horas e o bagaço $70{ }^{\circ} \mathrm{C}$ por 48 horas; trituração da amostras em moinhos de facas e; peneiramento.

\section{Determinação da proporção de engaço e bagaço}

Com as amostras de engaço e bagaço peneiradas, testou-se as proporções apresentadas na Tabela 1 para determinar qual delas seria a melhor para trabalhar no projeto. Para isso se fez uso de uma solução de cobre $0,1 \mathrm{~mol} / \mathrm{L}$ adicionadas a $1,0 \mathrm{~g}$ de biomassa, as mesmas foram agitadas por um horas e as concentrações foram determinadas através do espectrofotómetro

Tabela 1: Proporções das amostras

\begin{tabular}{ccc}
\hline Amostra & Bagaço & Engaço \\
\hline 1 & 0 & $100 \%$ \\
\hline 2 & $25 \%$ & $75 \%$ \\
\hline 3 & $50 \%$ & $50 \%$ \\
\hline 4 & $75 \%$ & $25 \%$ \\
\hline 5 & $100 \%$ & 0 \\
\hline
\end{tabular}




\section{Determinação do ponto zero (PCZ)}

A determinação do ponto zero é realizada para descobrir o $\mathrm{pH}$ em que a superfície do material apresenta carga neutra. Esse experimento consistiu em adicionar $1 \mathrm{~g}$ do biossorvente em $100 \mathrm{~mL}$ em agua destilada, em cada um dos dez béquers onde foram ajustados o pH no intervalo de 2 a 12 com o auxílio de soluções de $0,1 \mathrm{M}$ de ácido cloridrico e hidróxido de sódio, essa soluções ficaram sob agitação por 24 horas. Ao final do procedimento será medido o pH final da solução e com esses dados monta-se um gráfico do $\mathrm{pH}$ final versus $\mathrm{o} \mathrm{pH}$ inicial. $\mathrm{O}$ ponto de carga zero corresponde à média aritmética entre os pontos que tendem a um mesmo valor.

\section{Determinação dos íons metálicos a serem testados}

Devido a região da Serra Gaucha utilizar muito cobre na viticultura escolheu-se trabalhar o cobre II. As análises foram realizadas com o espectrofotômetro onde foi lida a absorbância no comprimento de onda 288 nanômetros $(\mathrm{nm})$.

\section{Ensaios de biossorção}

Todos os ensaios serão realizados em triplicatas para assim ser possível calcular o desvio padrão e analisar a dispersão dos pontos experimentais. Foram analisados os seguintes parâmetros: $\mathrm{pH}$, tempo de residência, cinética da reação e a isoterma de equilíbrio de adsorção. A técnica de determinação da concentração de cobre durante os experimentos foram realizadas a partir de uma curva de calibração de uma solução de feita com a solução de $1 \mathrm{M}$ de $\mathrm{CuSO}_{4}$ no espectrofotometro LAMBDA ${ }^{\mathrm{TM}} 265$ UV/Vis (PerkinElmer) no comprimento de 280 nm (nanômetros).

\section{Ensaio de $\mathrm{pH}$}

O experimento foi realizado testando os $\mathrm{pH}$ 2, 4, 6, 8, 10 e 12 em uma solução contendo biossorvente e solução de cobre sob agitação por 24 horas. Para a correção de $\mathrm{pH}$ foram utilizadas as soluções de hidróxido de sódio $(\mathrm{NaOH})$ e de ácido clorídrico $(\mathrm{HCl})$. Os ensaios foram finalizados com a filtração e análise das soluções foram feitas no espectrofotometro LAMBDA ${ }^{\mathrm{TM}} 265$ UV/Vis (PerkinElmer) no comprimento de $280 \mathrm{~nm}$ (nanómetros).

\section{Ensaio de tempo de residência}

Com a determinação do pH ideal a partir dos dados anteriores foi ajustado os valores de $\mathrm{pH}$ nos erlenmeyers. As amostras contendo $5 \mathrm{~g}$ de biomassa, $1 \mathrm{ml}$ de solução $1,0 \mathrm{M}$ de $\mathrm{CuSO}_{4}$ e $100 \mathrm{~mL}$ de água destilada a $25^{\circ} \mathrm{C}$ foram colocadas sob agitação nos tempos de 30, 60 e 90 minutos. Posteriormente as amostras foram filtradas e analisadas no espectrofotometro LAMBDA TM 265 UV/Vis (PerkinEImer) no comprimento de $280 \mathrm{~nm}$ (nanómetros).

\section{Determinação das isotermas de biossorção}

O equilíbrio do processo de adsorção dos íons $\mathrm{Cu}^{2+}$ pela biomassa da uva foi avaliado segundo os modelos de Langmuir e Freundlich, a $23^{\circ} \mathrm{C}$. A isoterma de 
Langmuir descreve um sistema de adsorção e dessorção em que a extenção da cobertura de adsorvato é limitada pela formação de uma única camada na superfíce do adsorvente (THOMAS; CRITTENDEN, 1998). A forma linearizada da equação de Langmuir está apresentada a seguir (FEBRIANTO et al., 2009):

$$
\frac{C_{e}}{q_{e}}=\frac{1}{q_{m} K}+\frac{C_{e}}{q_{m}}
$$

onde $\mathrm{C}_{\mathrm{e}}$ é a concentração de metal no equilíbrio ( $\mathrm{mg} / \mathrm{L}$ );

$\mathrm{q}_{\mathrm{e}}$ é a capacidade de adsorção no equilíbrio, $\mathrm{q}_{\mathrm{m}}$ é a capacidade de adsorção máxima correspondente à cobertura total da superfície do material adsorvente pelo adsorvato (ambas em mg/g); e K é a constante de Langmuir (L/ mg).

A isoterma de Freundlich assume que a superfície do adsorvente é heterogênea em termos de distribuição da energia de adsorção, entendida como a energia de interação entre o adsorbente e o absorvato. Além disso, os sítios que possuem a mesma energía de adsorção são agrupados entre si, formando sítios de adsorção que são independentes uns dos outros, não havendo interação entre eles. O modelo de Freundlich assume adsorção em multicamadas e supõe que esse processo seja ilimitado, ou seja, não prevê a saturação do adsorvente (CASTELLAN, 1986; DO, 1998; MONTANHER, 2009). A forma linearizada da isoterma de Freundlich está descrita abaixo:

$$
\log q_{e}=\log K_{F}+\frac{\log C_{e}}{n}
$$

onde $\mathrm{K}_{\mathrm{F}}$ e $\mathrm{n}$ (adimensional) são constantes que dependem da temperatura e estão relacionadas à capacidade de adsorção e à intensidade de adsorção (MONTANHER, 2009).

$\mathrm{O}$ valor de $\log \mathrm{K}_{\mathrm{F}}$ é equivalente ao $\log \mathrm{q}_{\mathrm{e}}$ quando $\mathrm{C}_{\mathrm{e}}$ é igual a um. No entanto, em outros casos em que o valor de $n$ seja diferente de um, a unidade de $\mathrm{K}_{\mathrm{F}}$ depende das unidades nas quais os parâmetros $q_{e}$ e $C_{e}$ estão sendo expressos (FEBRIANTO et al., 2009).

\section{DISCUSSÃO E RESULTADOS}

\section{Determinação da proporção de engaço e bagaço}

A Tabela 2 apresenta a quantidade de cobre removido para as diferentes composições testadas onde a melhor composição a se trabalhar é $50 \%$ engaço e bagaço (amostra 3), seguida pela composição $25 \%$ bagaço e $75 \%$ engaço (amostra 2). Com isso, definiu-se que a composição 50/50 seria utilizada nos ensaios posteriores. 
Tabela 2: Remoção de cobre por amostra

\begin{tabular}{cccc}
\hline Amostra & Bagaço & Engaço & \% Remoção de cobre \\
\hline 1 & 0 & $100 \%$ & $87,71 \pm 0,52$ \\
\hline 2 & $25 \%$ & $75 \%$ & $92,52 \pm 1,1$ \\
\hline 3 & $50 \%$ & $50 \%$ & $94,85 \pm 0,20$ \\
\hline 4 & $75 \%$ & $25 \%$ & $83,77 \pm 0,24$ \\
\hline 5 & $100 \%$ & 0 & $87,45 \pm 3,20$ \\
\hline
\end{tabular}

\section{Caracterização do biossorvente}

$\mathrm{O}$ ponto de carga zero corresponde que o $\mathrm{pH}$ se mantém constante, depois do sistema ter atingindo o equilibrio.

A Figura 2 apresenta a relação entre $\circ \mathrm{pH}$ inicial e o final das soluções. A partir desses dados foi possível calcular o ponto de carga zero fazendo-se uma média aritmética dos pontos que o $\mathrm{pH}$ final se mantêm constante, nesse caso foi 5,9. Quando um material sólido entrar em contato com uma solução líquida com pH abaixo do PCZ, a superfície é carregada positivamente e um grande número de ânions é adsorvido para balancear as cargas positivas. Assim, os adsorventes são mais eficazes para a remoção, por exemplo, de materiais aniônicos (RIBEIRO et al., 2011).

Figura 2: Determinação do ponto de carga zero.

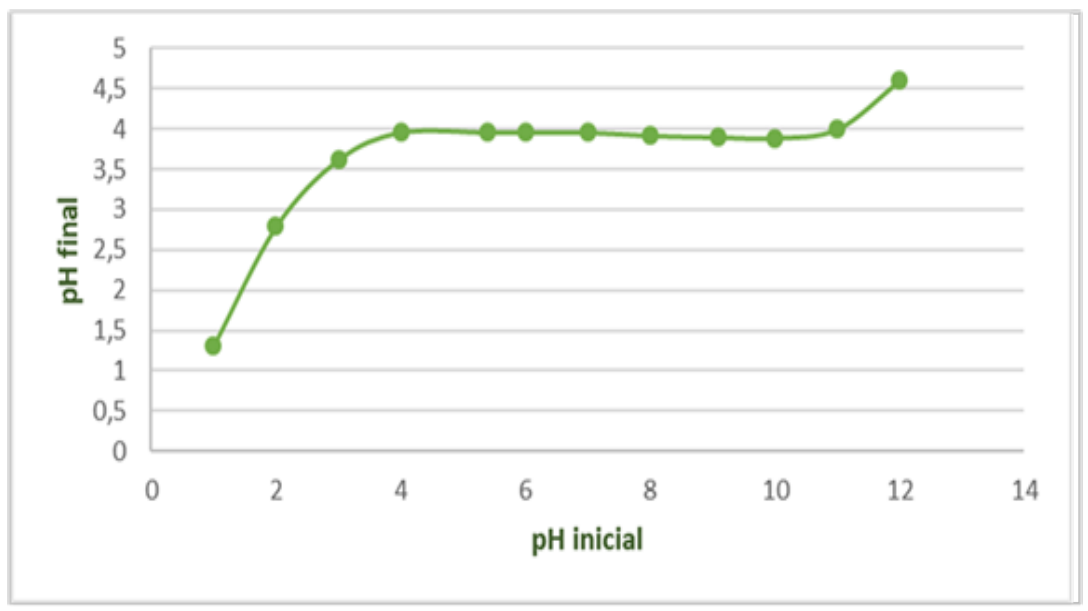

\section{Ensaios de biossorção}

\section{Determinação do pH}

Para avaliar a capacidade de remoção do cobre quando em contato com a biomassa da uva foram realizados testes em seis diferentes tipos de $\mathrm{pH}: 2$ a 12 . Os resultados obtidos no estudo de remoção do cobre pela biomassa tratadas com $\mathrm{HCl}$ e $\mathrm{NaOH}$, em pH 2,4,6,8,10 e 12 são apresentados na Figura 3. 
Figura 3: Determinação do $\mathrm{pH}$ ideal

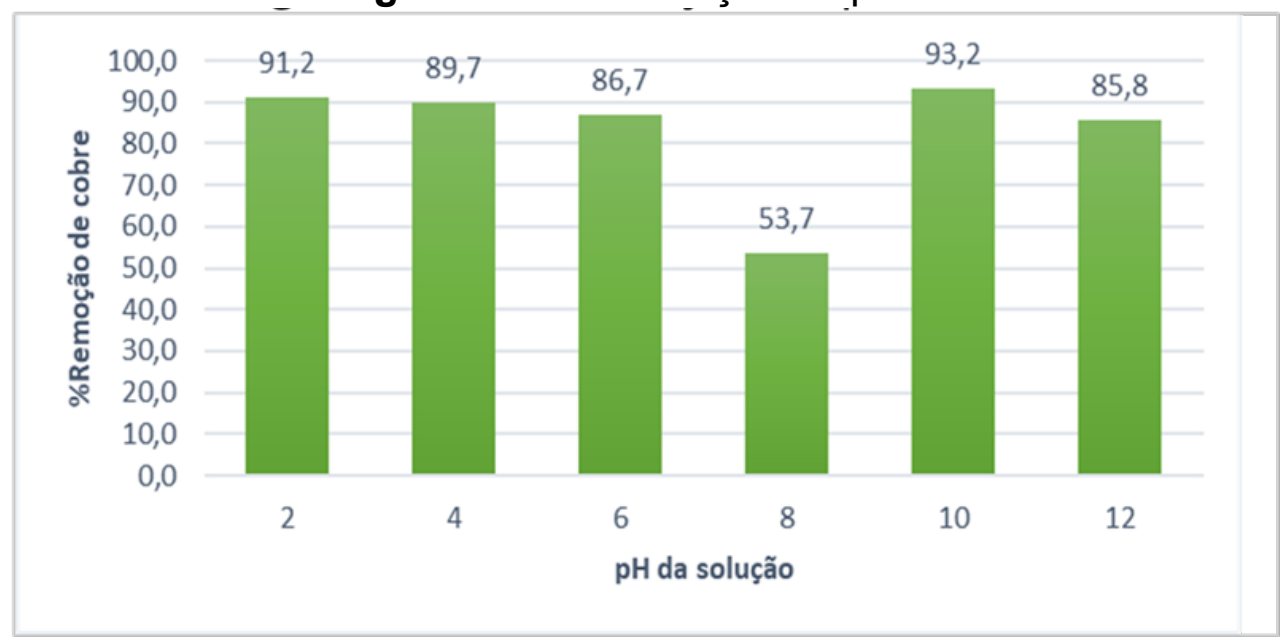

Depois de realizada as três repetições padronizadas para o experimento, a máxima da capacidade de adsorção para os metais em estudo $(\mathrm{Cu})$ ocorreu no pH próximo de 10 , para valores de $\mathrm{pH}$ inferiores a 10 ocorreram um decréscimo na remoção de metal.

Caretta (2010) explica que devido à natureza dos grupos orgânicos presentes no biossorvente o processo de adsorção deve ocorrer por um processo de troca-iônica entre as espécies em solução e o hidrogênio presente nos grupos - $\mathrm{COOH}$ do ácido péctico e dos ácidos orgânicos pequenos e das proteína, como também pelos grupos $\mathrm{OH}$ fenólicos da lignina.

Os mecanismos ocorridos durante a retenção de íons metálicos em um biossorventes de origem vegetal estão diretamente relacionados aos grupos funcionais químicos existentes no material. Esses grupos normalmente estão presentes em estruturas contidas na parede celular do biomaterial, que engloba macromoléculas de celulose organizadas na forma de microfibras cercadas por hemiceluloses, lignina, pectina e pequenas porções de proteínas vegetais (VAGHETTI, 2009).

O comportamento observado para capacidade de biossorção da biomassa pode ser explicado pelo fato das espécies metálicas estarem competindo entre si por sítios ativos da superfície da biomassa (NASCIMENTO et al., 2014).

A baixa remoção em $\mathrm{pH}$ ácidos e elevadas em $\mathrm{pH}$ básicos pode ser em decorrência da concorrência entre $\mathrm{OH}$ e as espécies de metais pela superfície do biossorvente (CONCEICÃO, 2014 apud NUNES et al., 2014).

A alta remoção em pH baixo se deve ao processo de precipitação e não de adsorção.

\section{Tempo de residência}

A Figura 4 apresenta a influência do tempo de residência sobre o percentual de remoção de cobre em solução. 
Figura 4: Determinação do tempo de residência

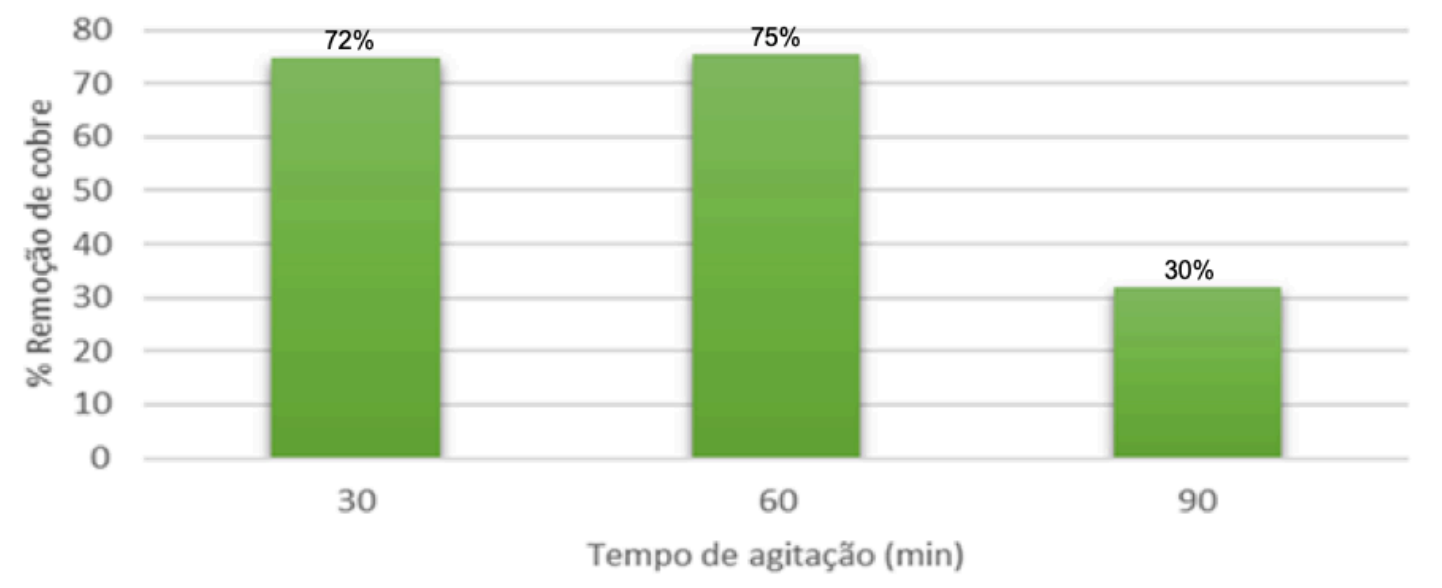

Com base nos dados obtidos, definiu-se 30 min como o tempo de contato ideal entre adsorvente e adsorvato. Nesse tempos o percentuais de remoção obtidos foram de $72 \%, 75 \%$ e $30 \%$ para 30 minutos, 60 minutos e 90 minutos, respectivamente. 0 tempo escolhido foi de 30 minutos tal justificativa se dá pelo fato de que tempos muito grandes devem ser evitados visando diminuir custos energéticos referentes ao processo de agitação da mistura.

O baixo valor de remoção de cobre no tempo de 90 minutos, indica a saturação dos poros o que independem dos mesmos removerem os íons de cobre na solução.

\section{Determinação das isotermas de biossorção}

As isotermas de Langmuir e de Freundlich para a adsorção de íons $\mathrm{Cu}^{2+}$ pelo bagaço de uva, a $23{ }^{\circ} \mathrm{C}$ (FIGURA 5 e 6). As isotermas foram constituídas a partir de uma curva de calibração construída com solução de $\mathrm{CuSO}_{4}$,analisado o comprimento de onda de $280 \mathrm{~nm}$.

Figura 5: Isoterma de Langmuir

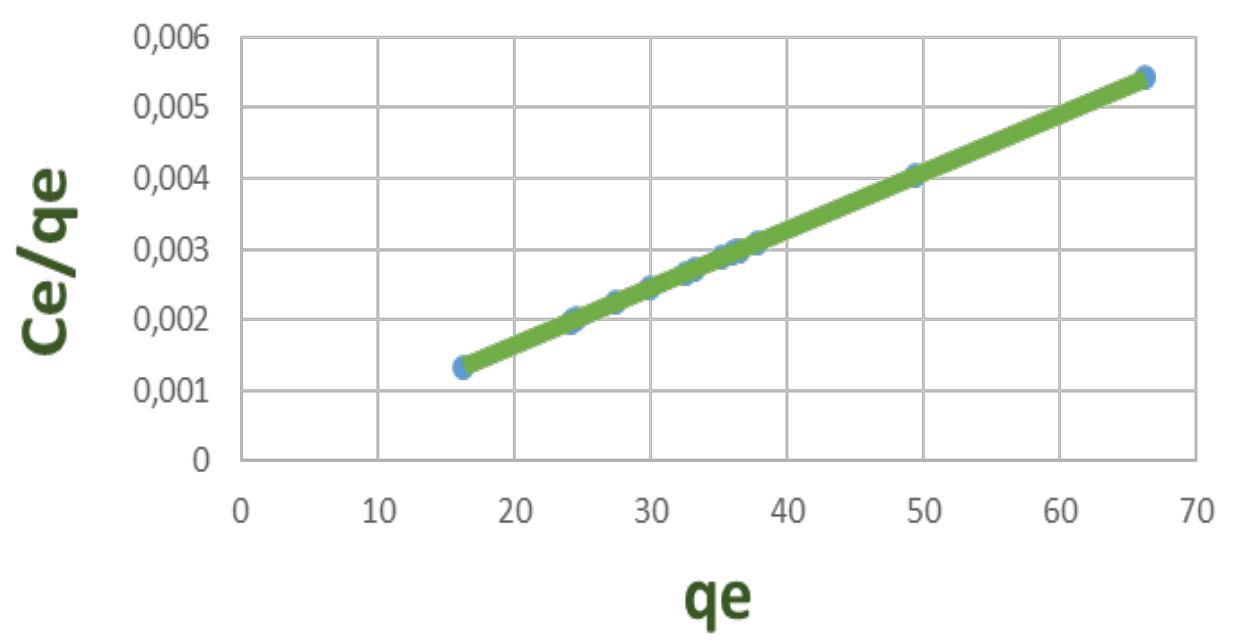


Figura 6: Isoterma de Freundlich

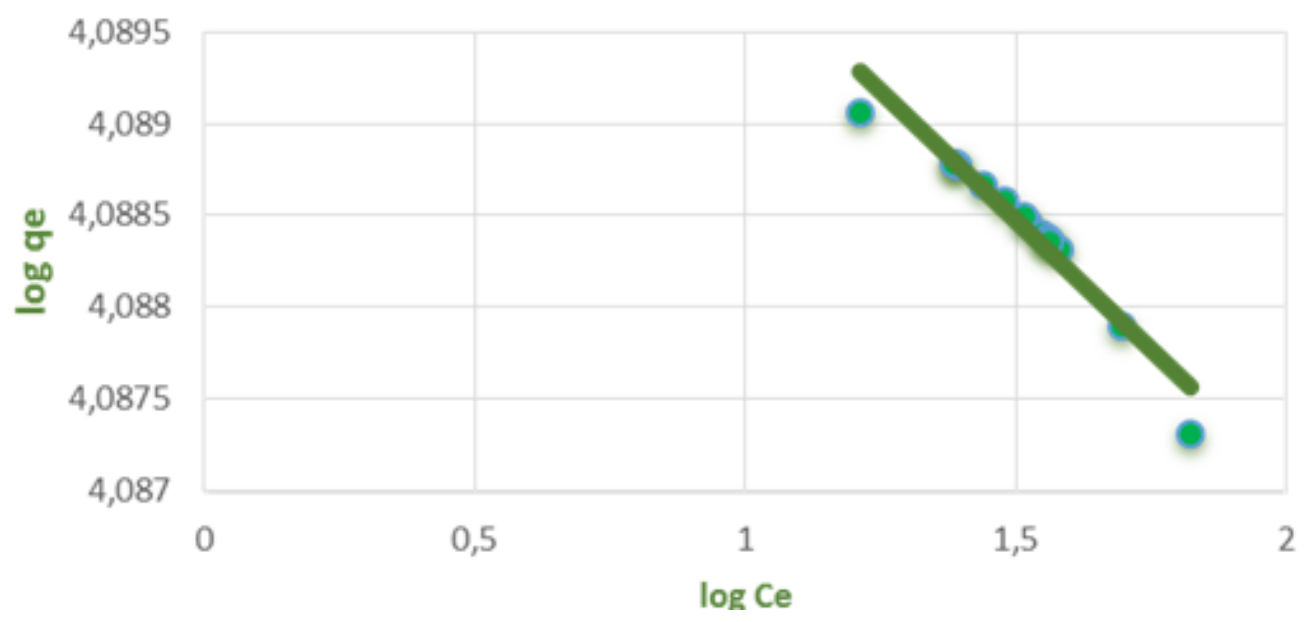

Os dados apresentados na Tabela 3 demonstram que o modelo de isoterma de Langmuir foi o que apresentou o melhor ajuste aos dados experimentais de equilíbrio. Isso mostra que biossorção do cobre ocorreu em sítios homogêneos e específicos da biomassa da uva e indica que a adsorção foi de natureza química. Deste modo, o modelo de isoterma de Langmuir pode ser utilizado para representar os dados experimentais de equilíbrio da adsorção de cobre. A máxima capacidade de adsorção na monocamada (qm) foi de $10.000 \mathrm{mg} \mathrm{g}^{-1}$ obtidos à $298 \mathrm{~K}$ (Tabela 3).

Tabela 3: Parâmetros das isotermas de Langmuir e Freundich

\begin{tabular}{|l|l|l|l|}
\hline \multicolumn{2}{|c|}{ Langmuir } & \multicolumn{2}{c|}{ Freundich } \\
\hline $\mathrm{K}_{\mathrm{L}}(\mathrm{L} / \mathrm{mg})$ & 5,0 & $\mathrm{~K}_{\mathrm{F}}\left(\left(\mathrm{mg} \mathrm{g}^{-1}\right)\left(\mathrm{L} \mathrm{mg}^{-1}\right)^{1 / n}\right)$ & 1.000 \\
\hline $\mathrm{q}_{\mathrm{m}}\left(\mathrm{mg} \mathrm{g}^{-1}\right)$ & 10.000 & $\mathrm{~N}$ & 1,25 \\
\hline $\mathrm{R}_{\mathrm{L}}$ & 0,995 & $\mathrm{R}^{2}$ & 0,9456 \\
\hline $\mathrm{R}^{2}$ & 1 & & \\
\hline
\end{tabular}

O parâmetro $k_{L}$ do modelo de Langmuir, que corresponde ao inverso da concentração na fase líquida onde a capacidade de adsorção é $0,2 \mathrm{qm}$, mostrou que maiores valores de saturação na monocamada (qm). O fator de separação $R_{L}$ da isoterma de Langmuir, indica que o processo é favorável uma vez que $0<R_{\mathrm{L}}<1$.

\section{CONCLUSÃO}

Com base nos resultados obtidos, a utilização da biomassa da uva como adsorvente nas diferentes formas testadas mostrou-se uma alternativa possível para a remoção da cobre de efluentes.

Em relação aos ensaios de absorção, pode-se concluir que a capacidade de adsorção depende do $\mathrm{pH}$ inicial da solução e do tempo de contato, onde os valores mais adequados para esses parámetros foram $\mathrm{pH} 10$ e 30 minutos de contato $\mathrm{A}$ isoterma de Langmuir foi a que melhor descreveu o processo de adsorção, indicando que o processo estudado é favorável. Os resultados apresentados nesse estudo demonstraram que a biomassa da uva contendo ( $50 \%$ de engaço e $50 \%$ bagaço) pode ser utilizado para a adsorção de íons cobre, porém outros estudos precisam ser realizados de modo a promover um maior percentual de remoção do adsorvato e também para analisar outros 
parametros como concentração do absorvato, granulometría, estudos sobre a cinética e a competitividade de outros íons metálicos com ese biossorvente.

A simplicidade da aplicação da técnica, ou seja, deixar o efluente junto com o biossorvente por 30 minutos de contato em pH 10 e posteriormente filtrar o mesmo permite que a remoção de cobre seja eficiente em 93,2\%. Apesar do alto consumo enérgético durante o processo de secagem da biomassa, a grande disponibiladade da matéria prima usada como biossorvente, o baixo custo durante o processo de adsorção a rápida adsorção demonstram que a utlização da biomassa da uva biossorvente é uma alternativa de alternativa na remoção metais, como o cobre dos efluentes.

\section{REFERÊNCIAS}

BHARGAVA, Atul; CARMONA, Francisco; BHARGAVA, Meenakshi; SRIVASTA, Shilpi. Approaches for enhanced phytoextraction of heavy metals. Journal of Environmental Management. v.105, n.1, p.103-120, agosto. 2012.

CARETTA, T. O. Avaliação do potencial das cascas de maracujá amarelo e de mexerica como biossorventes de metais pesados. 2010. 64 f. Dissertação (Mestrado em Química dos recursos naturais) Universidade Estadual de londrina, Londrina 2010.

CASTELLAN, G. Fundamentos de Físico-Química. Rio de Janeiro: LTC, 1986, p. 460462.

FERRARI, Valdecir. A sustentabilidade da vitivinicultura através de seus próprios resíduos. 2010. 26 f. TCC (Graduação) - Curso de Bacharel em Ciências Econômicas, Universidade de Caxias do Sul,Bento Gonçalves, 2010. Disponível em:http://www.ufrgs.br/ agronomia/materiais/userfiles/ArtigoResiduodeuva .pdf. Acesso em: 13 nov. 2017.

FEBRIANTO, J.; KOSASIH, A.N.; SUNARSO, J.; JU Y.-H.; INDRASWATI, N.; ISMADJI, S. Equilibrium and kinetic studies in adsorption of heavy metals using biosorbent: A summary of recent studies. Journal of Hazardous Materials, v. 162, 2009, p. 616-645.

GUIJARRO-ALDACO, Alejandro; HERNANDEZ-MONTOYA, Verginia;

BONILLAPETRICIOLET, Adrian; MONTES-MORAN, Miguel; MENDOZA-CASTILLO, Didilia. Improving the Adsorption of Heavy Metals from Water Using Commercial Carbons Modified with Egg Shell Waste. Industrial Engineering Chemistry. Research. v.50, n.15, p.9354-9362, jun. 2011.

IBRAVIN. Safra de uva 2017 é recorde no Rio Grande do Sul. 2017. Disponível em: http://www.ibravin.org.br/Noticia/safra-de-uva-2017-e-recorde- no-rio-grande-do-sul/281. Acesso em: 13 dez 2017.

KIM, Tae-Young; PARK, Sun-Kyu; CHO, Sung-Yong; KIM, Hwan-Beom; KANG, KING, P; SRINIVAS, P; KUMAR, Y. P; PRASAD, V. S. R. K. Sorption of copper(II) ion from aqueous solution by Tectona grandis I.f. (teak leaves powder). Journal of Hazardous Materials. v.136, n.1, p.560-566, jan. 2006.

MONTANHER, S. F. Utilização da biomassa de bagaço de laranja como material 
sorvente de íons metálicos presentes em soluções aquosas. 2009. 135 f. Tese de doutorado - Centro de Ciências Exatas, Universidade Estadual de Maringá, Maringá, 2009.

NASCIMENTO, J. M.; SILVA, B.S.; CHAVES, M. D.; OLIVEIRA, J. D. Biossorção dos íons $\mathrm{Cd} 2+$ e Pb2+ utilizando casca de pequi (Caryocar brasilense Camb) Modificada com acido cítrico. Revista Ciências Ambientais, Canoas v. 8 n. 1, p. 57-69, 2014.

NUNES D. D. A. REZENDE, J. C. T. REIS, E. N. JESUS, E. SILVA, A. S. PAGANO, R. L. Uso de mesocarpo de maracujá como biossorvente de $\mathrm{cr}(\mathrm{vi})$. In Congresso Brasileiro de Engenharia Química, 20.. 2014, Florianopolis. Anais... Santa Catarina COEBQ 2014. P.18.

OLIVEIRA, R; SILVA, R C. O. Biossorção de cromo (VI) utilizando cascas de jabuticaba. 2011. 36 f. Trabalho de Conclusão de Curso (Bacharelado em Química) Curso de Bacharelado em Química, Universidade Tecnológica Federal do Paraná, Pato Branco, 2011.

RIBEIRO, G. A. C. et al. Casca de arroz in natura e tratada com ácido nítrico como adsorventes para remoçao do corante têxtil violeta brilhante remazol. In: CONGRESSO BRASILEIRO DE QUÍMICA, 51., 2011. São Luís.

SCHÄFFER, Naihana. Caracterização de Resíduos Vitivinícolas e Compostos

Orgânicos Comerciais da Serra Gaúcha. 2015. 89 f. Dissertação (Mestrado em Ciência do Solo) - Faculdade de Agronomia, Universidade Federal do Rio Grande do Sul, Porto Alegre, 2015.

SCHUMACHER, Werner. A desengaçadeira e o gosto de engaço. Adega, v. 23, 2007. Disponível em:http://revistaadega.uol.com.br/artigo/a-desengacadeira-e-o-gosto-deengaco _7415.html\&gt;. Acesso em: 13 dez 2017.

SEOLATTO A, Câmara M, Tavares CRG, Cossich ES, SILVA EA. Remoção de níquel(II) de soluções aquosas pela biomassa Sargassum filipendula em múltiplos ciclos de sorção dessorção. Acta Scientiarum.Technology. 2009; (31 P1): p.57-64.

THOMAS, W. J.; CRITTENDEN, B. Adsorption technology and design. Oxford: Butterworth-Heinemann, 1998, p. 1-38.

THOMÉ, Luciara Ciane Port. Bioacumulação de íons de $\mathbf{P b}+2$ na macrófita Salvinia auriculata. Toledo: UNIOESTE, 2007. 87 p. Dissertação (Mestrado)- Programa de PósGraduação em Engenharia Química, Universidade Estadual do Oeste do Paraná, Toledo, 2008.

TOURNOUR, H. H., Segundo, M. A., Magalhães, L. M., Barreiros, L., Queiroz, J., \&amp; Cunha, L. M. 927 (2015). Valorization of grape pomace: Extraction of bioactive phenolics with antioxidant 928. properties. Industrial Crops and Products, 74, 397-406. Disponivel em: https://doi.org/10.1016/j.indcrop.2015.05.055. Acesso em: 18 dez. 2017. 
VAGHETTI; J. C. P. Utilização de biosorventes para remediação de efluentes aquosos contaminados com íons metálicos. 2007. 78 f. Tese (Doutorado em Química) - Instituto de química, Universidade federal do Rio Grande do Sul, Porto Alegre, 2009.

YONG; KIM, Sang-Done; KIM, Seung-Jai. Adsorption of Heavy Metals by Brewery Biomass. Korean Journal of Chemical Engineering. v.22, n.1, p.91-98, nov. 2005.

Recebido em: 05/05/2019

Aprovado em: 25/07/2019 